\title{
On the origins of isomorphous replacement in protein crystallography
}

\author{
Istvan Hargittai ${ }^{1}$
}

Accepted: 9 February 2022 / Published online: 16 February 2022

(c) The Author(s), under exclusive licence to Springer Science+Business Media, LLC, part of Springer Nature 2022

The determination of the structures of large biological molecules, such as the alpha-helix of proteins, the double helix of DNA, the globular structure of hemoglobin and myoglobin, and the structure of twofold symmetry of the photosynthesis reaction center, is among the stellar achievements in the history of twentieth century science. The pioneering work of Max F. Perutz (1914-2002, Fig. 1) in the application of isomorphous replacement was the start of great successes in protein crystallography. The essence of the technique is succinctly, but clearly described in the Perutz quotes below. Perutz and John C. Kendrew (1917-1997) received the Nobel Prize in Chemistry in 1962 "for their studies of the structure of globular proteins." This formulation was accurate. The Nobel Prize institution is usually careful in delineating the achievements of the awardees from contributions by others in the same area of science. In this case, it did not say anything about discovery, only about "studies."

Perutz applied the isomorphous replacement technique for hemoglobin and Kendrew for myoglobin, but they did not discover it. In this connection, it is remarkable that Aaron Klug (1926-2018) stated in 2003 that "Perutz is often misquoted as having discovered the isomorphous replacement method." (emphasis by me) [1]. In reality, Perutz himself expressed it unambiguously that it was his discovery, at least for the investigation of proteins. However, the technique did not just pop up from nowhere and it is of interest to understand its gestation. In this communication, I share relevant sections of my conversations and correspondence with three of the principal characters involved in this matter, viz., Perutz, Francis Crick (1916-2004, Fig. 1), and Aaron Klug (1926-2018), in the period between 1997 and 2003. I do this with a caveat: My account focuses on one segment of the history of isomorphous replacement in protein crystallography, but should not be construed as the history thereof.

Istvan Hargittai

stuceditor@gmail.com

1 Department of Inorganic and Analytical Chemistry, Budapest University of Technology and Economics, Budapest 1521, Hungary
For those interested in a more complete history, the present account is appended by additional references.

On September 17, 1997, I visited Max Perutz at the Laboratory of Molecular Biology of the Medical Research Council (MRC LMB) in Cambridge, UK, and recorded a long conversation with him. This conversation was printed in 1999 [2]. It was augmented (but not altered) in February 2000 during my wife's and my 3-month stay at the LMB, and published in 2002 [3]. Here is the relevant passage from the 1997 conversation:

Question: How much modeling went into the hemoglobin study?

Response: None. None at all. It was a question of solving the phase problem. I should perhaps say, though, that I did make an earlier model where I proposed what turned out to be alpha-helices strung out in parallel, and this turned out to be a complete nonsense. To solve the structure, I had to solve the phase problem, which was generally regarded as insoluble for such a large structure.

In 1953 I discovered that it could be solved by the method of isomorphous replacement. I compared the $\mathrm{X}$-ray diffraction pattern from a crystal of pure hemoglobin to one from hemoglobin to which I attached two mercury atoms. In 1936 J.M. Robertson in Glasgow had solved the structure of an organic dye with this method, but that dye contained 58 atoms while hemoglobin contains 10,000. Everybody believed that attaching a heavy atom to the protein wouldn't have any measurable effect on the diffraction pattern. I had measured, for some other purpose, the absolute intensity of reflections from the hemoglobin crystal, that is, the fraction of the incident beam that is diffracted. That told me that the scattering contributions of most of the light atoms, which are spread over a large volume, cancel by interference, while in a heavy atom the electrons would be concentrated at a point and they would all scatter in phase. Therefore, the heavy atom would make a measurable difference to the scattering 


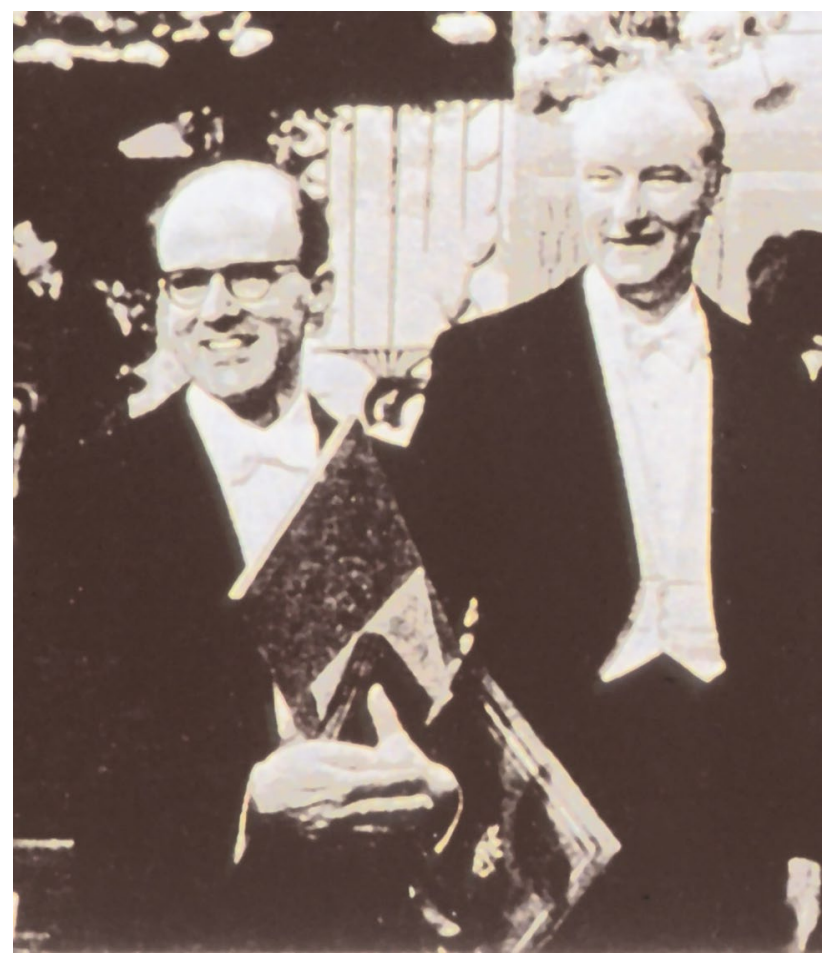

Fig. 1 Max F. Perutz and Francis Crick at the Nobel Prize award ceremony, Stockholm, December 10, 1962 (detail of a larger photograph courtesy of the late Lars Ernster)

and that was borne out by the first experiment I did. So I found that the phase problem could be solved by the heavy atom method. That was my life's most important discovery, because it opened the whole field of protein structure to X-ray analysis.

Francis Crick writes in his book, What Mad Pursuit [4], that he (Crick) might have been the first at the Cavendish Laboratory to suggest the use of the isomorphous replacement method in protein structure analysis. In 1947, Perutz and Kendrew formed the MRC Unit for Research on the Molecular Structure of Biological Systems (URMSBS) at the Cavendish Laboratory, at W. Lawrence Bragg's initiative, which, eventually, Crick and others joined. In 1962, they became an independent entity as the MRC LMB. I asked Crick in a letter of July 24, 2000, about the circumstances of the application of isomorphous replacement in protein crystallography. He responded in his letter of August 4, 2000. In my correspondence with Crick, 2000-2004, many issues came up and I am quoting here only the passages relevant to the present topic. He wrote [5]:

There is no doubt that Max was the first person to successfully use the method of isomorphous replacement on a protein crystal. However, at that time the idea of isomorphous replacement was well-known, and I am told that it had been used successfully for inorganic compounds such as the alums. I don't know who was the originator of the idea.

Bernal had apparently suggested in 1935 to Dorothy Hodgkin that she should try to compare zinc, cadmium and cobalt insulin, but that didn't work. My recollection is that after the Second World War, Dorothy tried to put iodine onto the tyrosines of insulin, but that didn't work either.

My contribution-before Max tried it-was to calculate that the method should, with luck, work for hemoglobin (or myoglobin) and to stress that this was the only method likely to enable them to solve protein structures. Up to that point Max was trying to use the 3D Patterson to solve the structure. I am not sure at the moment of the date of my little talk, which was part of a small meeting at the Cavendish, on protein crystallography, but it was probably 1951 or 1952 .

Parallel to the letter to Crick, I asked Perutz in a letter of July 24, 2000, a set of similar questions in connection with the history of the application of isomorphous replacement in protein crystallography. Perutz responded in a handwritten letter of August 15, 2000 [6]. I am communicating it facsimile (Fig. 2). It was the only hand-written document among those quoted here; the others were typed and sent mostly by fax.

\subsubsection{0}

Dear Dr Hargittai,

Thank you for your letter of 24 July. Crick may have mentioned isomorphous replacement with heavy atom in his seminar, but he certainly gave no reason why it should give measurable intensity changes in the face of the apparently overwhelming scattering contribution by the thousands of light atoms, nor did Bernal or Dorothy Hodgkin. That became apparent only when I measured the absolute intensities of reflections from a haemoglobin crystal. My result showed that more than $99 \%$ of the scattering contribution of the light atoms are extinguished by interference. On the other hand, the electrons of a heavy atom, being concentrated at a point, would all scatter in phase and therefore extinguish those of the light atoms.

Yours sincerely,

MF Perutz

Trying to fully understand how the idea of isomorphous replacement commenced for protein studies, I asked Crick, further, about it in a letter of August 8, 2003. His response of August 29, 2003 was [7]: 


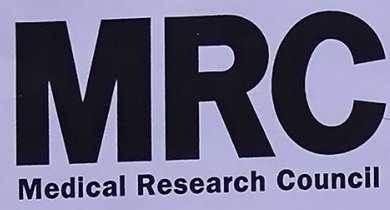

Der Da Hargithai,

\section{MRC Laboratory of Molecular Biology}

Hills Road

Cambridge, CB2 2QH

England

Tel: $\quad+44$ (0) 1223248011

Fax: $\quad+44$ (0) 1223213556

Dr. M. F. Perutz,

Direct Line: +44 (0)1223 402200

Secretary: +44 (0) 1223402214

$15 \cdot 8 \cdot 2000$

\section{Thauls zon for pas letter of 24 Jults.}

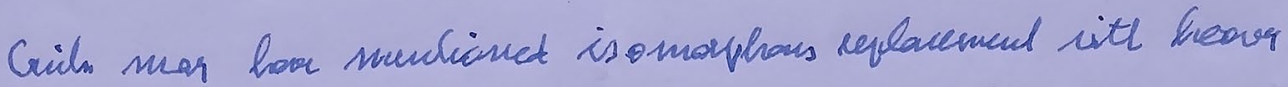

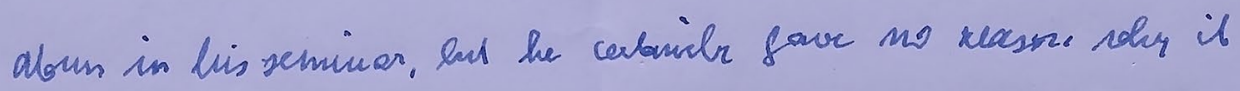

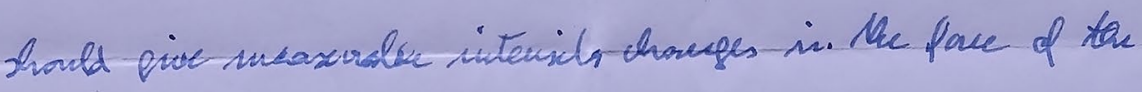

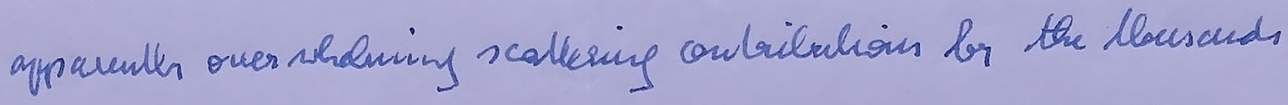
of light aban, na did Bounal a Daother Madghir. Tlad become

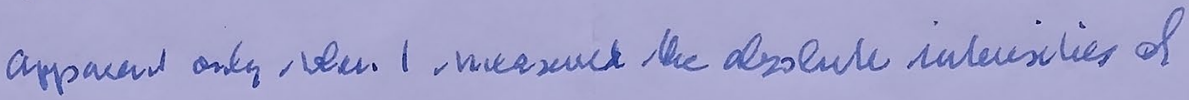
ufferion. foon a haunglebir cuptel. Ity resull sorred thed nove than 99\% of the seattering conbilatisas of the liget abrus are endiuguished hm -interleveure. On the teer havd,

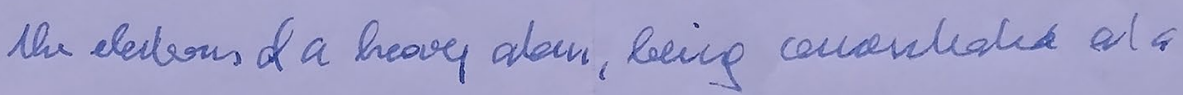
roint, would ale scatter in phase ant therfore ontwigh there of the light alouss.

$$
\text { Yerers simexels }
$$

$$
\text { HF Perute }
$$

Fig. 2 Max F. Perutz's letter of August 15, 2000, to the author 
About Max Perutz. He was certainly not the first to suggest the method of isomorphic replacement for proteins, but he was the first to make it work and this transformed the field. I don't think he was especially quick in applying it. This is because it is not easy to do. We had taken on Vernon Ingram to develop chemical methods to do this, so it was lucky Max got a supply of sickle cell hemoglobin AND the $\mathrm{Hg}$ worked. (emphasis in Crick's letter) He did a wonderful job of sticking with hemoglobin till he had proved his theory of its action correct. Also in running the MLB (sic, should read LMB) so well and so smoothly.

Crick's writing appears terse, but by then he was "in poor health." Nonetheless, he invited us for a visit in February 2004 to their home in La Jolla, California, when we were to be staying for a few weeks at Caltech in Pasadena. On the occasion of that visit, less than 6 months before his death, he was in great spirit and we discussed many issues [8], but Perutz and isomorphic replacement were not among them.

Finally, I asked Aaron Klug in a letter of October 21, 2003 , about the origins of the idea of applying isomorphous replacement to protein studies and he responded in a letter of November 24, 2003 [1]:

On the question of Perutz's contribution, there is no question of the importance of his contribution. I wrote about this in my "Retrospective" in Science on Perutz (really an obituary) in about April 2002. Perutz is often misquoted as having discovered the isomorphous replacement method. He did not. Bernal pointed the way in his Tilden Lecture to the (British) Chemical Society in 1939, and the issue was discussed in his correspondence with Dorothy Hodgkin.

What Perutz did was to demonstrate experimentally that it could be implemented in haemoglobin. This was preceded by his measurements of the absolute intensities of scattering by haemoglobin which showed it was feasible. One mercury atom in the $\beta$ subunits of $\mathrm{Hb}$ was enough to determine phases.

Your remarks on Bernal are all pertinent. Moreover, he was the sort of man who quickly moved on from starting one subject to the next, which always appeared more exciting. When I came to Birkbeck in 1953, Bernal hadn't been pressing Harry Carlisle in his department to try isomorphous replacement. (Bernal had emphasized the importance of "constellations" of strong Xray reflections, but did not point a way of using them). Carlisle had developed an analytical approach which I thought unsound and said so. I advocated isomorphous replacement, but this was after I had read of Perutz's absolute intensity measurements, so I was not involved in the story, as you imply in your letter.

Distributing credit among several crystallographers about recognizing the possibility of isomorphic replacement for protein structures does not subtract anything from the significance of Perutz's pioneering contribution. Floating ideas do not make a discovery, carrying it to completion does. It appears that it was Perutz only who was willing and proved capable of doing the tremendous work needed for performing the first successful application of isomorphic replacement in protein crystallography. He paved the way also for Kendrew's Nobel Prize-winning myoglobin study, followed by numerous other studies.

The Historical Atlas of Crystallography, edited by José Lima-de Faria in 1990 [9], describes the development of the technique and it is especially valuable that it includes its pre-protein-crystallography history. J. Monteath Robertson (1900-1989) was a pioneer of the technique for small and medium size molecules, still far smaller than proteins. His pupils at the University of Glasgow became outstanding contributors to the field internationally. Both Soraya de Chadarevian's book, Design for Life ([10], p 125), and John Finch's, A Nobel Fellow on Every Floor ([11], p 346), highlight Perutz's contribution. To quote Finch's Timeline, "Max Perutz's X-ray diffraction photographs from crystals of mercury-haemoglobin demonstrated that the isomorphous replacement method could be used to solve protein structures." De Chadarevian adds that "As Bragg has remarked, there was "nothing original' in the idea of using the method for protein analysis, Bernal had pointed to this possibility many years before. Other groups had experimented with the method, providing important insights and tools. Perutz's achievement consisted in making the technique work ..." ([10], pp 125-126, with references).

\section{Appendix}

Additional references from the history of isomorphic replacement

This set of references is still only a selection of the large literature. It is based primarily on a relevant section of the International Tables for Crystallography [12] and Neil Isaacs's historical paper [13]. J.M. Cork used isomorphic replacement in 1927 for the elucidation of a series of alum structures [14]. J. Monteath Robertson demonstrated the utility of the technique on a series phthalocyanine structures in the mid-1930s [15]. Johannes M. Bijvoet and his associates provided further examples of the application of the technique in 1951 with the structure determination of strychnine sulfate pentahydrate [16]. Diverse examples of protein structure studies included those by David W. 
Green, Vernon M. Ingram, and Max F. Perutz in 1954 [17]; by David Harker in 1956 [18]; and by David M. Blow and Francis Crick in 1959 [19]. Finally, those studies are mentioned that are usually considered to be the first great successes of protein structures by the isomorphous replacement method, viz., myoglobin by John C. Kendrew et al. [20] and hemoglobin by Max F. Perutz et al. [21].

\section{References}

1. Aaron Klug's letter of November 24, 2003, to the author

2. Hargittai I (1999) Max Perutz. The chemical intelligencer $5(1): 16-21$

3. Hargittai I (2002) Candid science II: conversations with famous biomedical scientists. Edited by M Hargittai, Imperial College Press, London, Chapter 18, "Max F. Perutz," pp 280-295, actual quote, pp 288 and 290

4. Crick F (1988) What mad pursuit. BasicBooks, New York, p 50

5. Francis Crick's letter of July 24, 2000, to the author

6. Max F. Perutz's letter of August 15, 2000, to the author

7. Francis Crick's letter of August 29, 2003, to the author

8. Hargittai I, Hargittai M (2006) Candid science VI: more conversations with famous scientists, Imperial College Press, London, Chapter 1, "Francis Crick," pp 2-19

9. Lima-de-Faria J (1990) Historical atlas of crystallography. Dordrecht, etc: Kluwer for the International Union of Crystallography

10. De Chadarevian S (2002) Design for life: molecular biology after World War II. Cambridge University Press, Cambridge, UK

11. Finch J (2008) A Nobel fellow on every floor: a history of the medical research council laboratory of molecular biology. Cambridge, UK: MRC LMB
12. Vijayan M, Ramaseshan A (2006) 2.4. Isomorphous replacement and anomalous scattering. In International Tables for Crystallography, Volume B: Reciprocal space, Shmueli U., ed, Springer, Dordrecht, pp 264-275

13. Isaac N (2016) A history of experimental phasing in macromolecular crysallography. Acta Cryst D: Structural Biology 72:293-295

14. Cork JM (1927) LX. The crystal structure of some of the alums. The London, Edinburgh, and Dublin Philosophical Magazine and Journal of Science 4:688-698

15. Robertson JM (1937) X-ray analysis and application of Fourier series methods to molecular structures. Rep Prog Phys 4:332-367

16. Bokhoven C, Schoone JC, Bijvoet JM (1951) The Fourier synthesis of the crystal structure of strychnine sulphate pentahydrate. Acta Cryst 4:275-280

17. Green DW, Ingram VM, Perutz MF (1954) The structure of haemoglobin - IV. Sign determination by the isomorphous replacement method. Proceedings of the Royal Society A 225:287-307

18. Harker D (1956) The determination of the phases of the structure factors of non-centrosymmetric crystals by the method of double isomorphous replacement. Acta Cryst 9:1-9

19. Blow DM, Crick F (1959) The treatment of errors in the isomorphous replacement method. Acta Cryst 12:794-802

20. Kendrew JC, Dickerson RE, Strandberg BE, Hart RG, Davies DR, Phillips DC, Shore RG (1960) Structure of myoglobin. Nature 185:422-427

21. Cullis AF, Muirhead H, Perutz MF, Rossmann MG, North ACT (1961) The structure of haemoglobin VIII. A three-dimensional Fourier synthesis at $5.5 \AA$ resolution: determination of the phase angles. Proceedings of the Royal Society A 265:15-38

Publisher's Note Springer Nature remains neutral with regard to jurisdictional claims in published maps and institutional affiliations. 